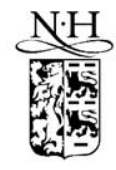

ELSEVIER
International Journal of Industrial Organization 21 (2003) 439-453
International Joumal of

Industrial

Organization

www.elsevier.com/locate/econbase

\title{
Follow-my-leader FDI and tacit collusion
}

\author{
Dermot Leahy*, Stephen Pavelin \\ University College Dublin, Economics Department, Belfield, Dublin 4, Ireland
}

Received 24 July 2001; received in revised form 15 February 2002; accepted 8 June 2002

\begin{abstract}
This paper presents a simple model to illustrate the following idea: domestic rivals may be motivated to set up foreign production in the same country because the replication of each other's foreign direct investment (FDI) facilitates collusive behaviour in the market in which they compete. This implies positive interdependence between firms' FDI decisions, i.e. foreign investment by one firm brings increased incentive for others to follow suit.

(C) 2002 Elsevier Science B.V. All rights reserved.
\end{abstract}

JEL classification: F23; L13

Keywords: Foreign direct investment; Tacit collusion; Oligopoly

\section{Introduction}

The study of foreign direct investment (FDI) has tended to focus on two reasons for locating in a particular country. First, firms are motivated by the search for lower costs of supplying a market. Second, firms may wish to gain improved access to that country's or some other country's market ${ }^{1}$. In this paper we

\footnotetext{
*Corresponding author. Tel.: +353-1-716-8551.

E-mail address: dermot.m.leahy@ucd.ie (D. Leahy).

${ }^{1}$ Buckley and Casson (1981) specify the optimal timing of FDI for a single firm by reference to costs, demands and market growth. The relationship between production costs, market access and strategic behaviour in determining FDI is modelled by Smith (1987), Horstmann and Markusen (1987, 1992) and by Motta (1992). Caves (1996) presents an excellent discussion of such standard explanations of multinational enterprises and FDI.
} 
complement these standard explanations by highlighting a possible third motive for FDI. Briefly put, the idea is this: domestic rivals may be motivated to set up foreign production in the same country because the replication of each other's foreign direct investment (FDI) facilitates collusive behaviour in the market in which they compete. This implies positive interdependence between firms' FDI decisions, i.e. foreign investment by one firm brings increased incentive for others to follow suit. So, we will highlight a mechanism that propagates FDI clusters.

Knickerbocker (1973) put forward the idea that firms' FDI is to some extent follow-my-leader in character. The main thrust of his argument is nicely encapsulated in the following quote (p.26):

"[F]irms A and B ... export competing products to foreign country X. Now, suppose A established a manufacturing subsidiary in $\mathrm{X}$. B, uncertain of production economies, if any, that A might gain by manufacturing locally, faces the possibility that it could be underpriced by $\mathrm{A}$ in the market place. By establishing its own manufacturing subsidiary, B can match the production costs of A and thereby preserve its market share should A resort to price competition."

The model to be presented here is very much in the same spirit as his story ${ }^{2}$, but is nevertheless a little different from Knickerbocker's vision. He saw uncertain foreign cost economies as a threat to the status quo in all markets (at home and abroad - if the firms initially export). Risk averse firms would seek to minimise the prospect of upsetting the balance of competition by replicating an initial FDI by one of their number. However, uncertainty about the foreign production environment plays no role in our model. Instead firms engage in follow-my-leader FDI because of foreign cost advantages that would threaten oligopolistic collusion if FDI was not replicated across firms.

\footnotetext{
${ }^{2}$ In fact Knickerbocker focussed upon a link between FDI and concentration, and specifically, how the latter affects the former. He hypothesised that follow-my-leader behaviour acts to bring about the highest levels of FDI at intermediate levels of concentration. Indeed, it is a hypothesis that has received some support from empirical studies (Knickerbocker, 1973; Caves and Pugel, 1980). The proposed reason for such a link is that tacit collusion is both the environment in which follow-my-leader behaviour flourishes, and typically found at intermediate levels of concentration: where concentration is too low, firms are too numerous to coordinate their activities; where concentration is too high firms can coordinate so as to maximise industry profits, and so surpass imitative behaviour. The model we will present here is not designed to describe a link between FDI and concentration - two-firm concentration is fixed throughout at $100 \%$. However, a straightforward extension (permitting firm numbers to vary exogenously) would yield the prediction for follow-my-leader FDI to be most likely at the higher levels of concentration. This is at odds with the link proposed elsewhere. The disparity arises because we impose tacit collusion as the only method of coordination available to firms. Thus we exclude the stronger form of collusion (the maximisation of industry profits) that, it is argued, acts to suppress FDI at the highest levels of concentration. So, an extension more in the spirit of Knickerbocker's work would permit the manner of coordination between firms to vary with concentration.
} 
Follow-my-leader FDI has received rather a lot of attention in the international business literature where it has been subjected to empirical testing. Knickerbocker (1973), Yu and Ito (1988) and Ito and Rose (1998) find evidence for it while Hennart and Park (1994) are more sceptical. By contrast, little has been written on this motive for FDI by economists. A notable exception is a recent paper by Head et al. (forthcoming) in which follow-my-leader FDI is driven by uncertainty and risk aversion. Unlike our paper, theirs is not concerned with the problem of sustaining tacit collusion.

It is worth making two further points before moving on. These concern the scope of the model to be presented. Firstly, the foreign production permitted is purely vertical in nature: the firms' foreign production is used only to serve the domestic market ${ }^{3}$. Thus, it is of the sort that replaces high cost domestic production with low cost foreign production, without seeking to gain entry into the foreign market, i.e. that typically associated with north-south FDI. In the context of US firms, a prime example would be their FDI into Mexico and other Central and South American nations.

Secondly, this model can be applied to firm behaviour other than FDI. This is because of how we characterise FDI in our model: (i) FDI does not affect the number of markets served by a firm; (ii) FDI involves a fixed cost in exchange for a per-unit saving. One may wish to characterise other investment (say in capital, research and development or in a distribution network) in the same way. If so, the follow-my-leader behaviour to be illustrated here will be applicable to a wider range of firm behaviour than simply FDI. ${ }^{5}$

The next section describes the model and gives results. Some concluding remarks are provided in Section 3.

\section{The model}

There are two countries, A and B, and two firms, 1 and 2. Both firms are initially based in A, where they each have a plant for the production of the same

\footnotetext{
${ }^{3}$ Here, firms will only ever face each other in one market, their domestic market. This means that we will not be discussing the impact that multimarket contact can have on the sustainability of collusion (for further discussion of these issues, see Bernheim and Whinston, 1990; Scott, 1993).

${ }^{4}$ Our model is consistent with not only this setting. For our model to hold, we require that the FDI does not bring about multimarket contact between the firms. Other settings consistent with our model include: two firms from different home countries considering FDI into a third country to which they would otherwise export; two firms making a locational choice between countries and selling to an integrated world market.

${ }^{5}$ Having said that, up to now it is in the form of FDI that follow-my-leader investment behaviour has attracted the most interest.
} 
homogeneous good. ${ }^{6}$ To fix ideas we will refer to A as the domestic country and to $\mathrm{B}$ as the foreign country and assume that all output is sold on the domestic market. Domestic demand is defined according to the following inverse demand function:

$$
p=\alpha-\beta\left(q_{1}+q_{2}\right)
$$

where $q_{i}$ is the output produced by Firm $i$. Firms must decide whether to abandon domestic production and replace it with foreign production by setting up a new plant in B. Marginal production costs are constant ${ }^{7}$. This takes the level of $c$ in country A, and of $c-r$ in country B. Thus if $r>0$, foreign production is relatively low cost. However, units produced abroad must be exported back to A for domestic consumption. The accompanying transport cost is a per-unit cost of $t$. So, if $r-t>0$, the foreign country offers a lower cost method of serving the domestic market, than does domestic production. Hence, the variable costs associated with the various options can be summarised as follows $(q=$ output dedicated to the domestic market):

$$
\begin{aligned}
& \text { non-FDI }: \quad V C=c q \\
& \text { FDI }: \quad V C=(c-r+t) q
\end{aligned}
$$

There is a once-off, fixed and sunk ${ }^{8}$ cost associated with FDI, the cost of building the new plant, $G$. For simplicity, we will normalise $(\alpha-c) / \beta$ as unity and refer to $(r-t) / \beta$ as $b$.

Firms face each other in the domestic market over an infinite number of time periods. So, each firm must decide upon its FDI strategy in order to maximise the present value of the stream of future profits it can expect to accrue. Future profits are discounted and the discount factor is represented by $\delta$.

The game played out by the firms is as follows: prior to the first of their infinite number of meetings in the market, they each simultaneously decide whether to undertake FDI, and any investment is completed; prior to every proceeding output-setting stage any firm that has thus far decided against FDI, has the chance to change its mind and invest. Thus, the decision to undertake FDI is irreversible (owing to the sunk nature of the fixed cost), but the decision to not do FDI is reversible. Furthermore, we assume that all FDI is observable to both firms when setting output.

First of all we will present results given the assumption that collusive behaviour

\footnotetext{
${ }^{6}$ The assumption that the goods produced are identical is made simply to save on parameters. The model generalises straightforwardly to the case of imperfect substitutes.

${ }^{7}$ Constant marginal costs imply that firms will never wish to produce in both locations simultaneously. This assumption is made to keep the analysis as simple as possible.

${ }^{8}$ This means that the cost of setting up the foreign plant is in no way proportional to output and is non-recoverable.
} 
is not permitted. Then, we permit tacit collusion and show how this changes things.

\subsection{Collusion excluded}

Each firm chooses whether to undertake FDI so as to maximise the present value of their profit stream. This is followed by infinitely repeated Cournot competition $^{9}$, with the production costs of the firms having been determined by their FDI decisions. The present value of profits for each firm, for each combination of FDI strategies, are as follows:

Firm $i-$ no FDI, $\quad$ Firm $j-$ no FDI: $\quad \pi_{i}=\pi_{j}=\frac{1}{1-\delta} \frac{\beta}{9}$

Firm $i-$ FDI, $\quad$ Firm $j-$ no FDI: $\quad \pi_{i}=\frac{1}{1-\delta} \frac{\beta(1+2 b)^{2}}{9}-G$

$$
\pi_{j}=\frac{1}{1-\delta} \frac{\beta(1-b)^{2}}{9}
$$

Firm $i$-FDI, $\quad$ Firm $j-$ FDI: $\quad \pi_{i}=\pi_{j}=\frac{1}{1-\delta} \frac{\beta(1+b)^{2}}{9}-G$

We present the sub-game perfect equilibria in $b, g$ space $^{10}$ (where $g=(G / \beta)(1-$ $\delta)$ ) in Fig. 1 (Firm 1's strategy is given first, $\mathrm{F}=\mathrm{FDI}, \mathrm{O}=$ no FDI). Remember: $b$ is a measure of the variable cost saving offered by foreign production; $g$ is a measure of the extra fixed cost associated with a foreign plant ${ }^{11}$.

The key feature of these results is negative interdependence between the firms' FDI decisions. FDI by a firm reduces its rival's incentive to do FDI. When the marginal cost of Firm 1 falls as a result of FDI, its output rises. The resulting fall in the market share of Firm 2 reduces the marginal benefit to that firm of a fall in its own marginal costs, thus reducing its incentive to undertake FDI. While negative interdependence holds at all parameter values it is only in the central region that one firm invests abroad while the other remains domestic.

In the next section we permit collusive behaviour. We will show that, in that

\footnotetext{
${ }^{9}$ From this point on, the terms Cournot and competitive will be used interchangeably. Thus, when we refer to competitive outcomes, this should not be taken to mean perfect competition. In Cournot competition output is priced in excess of marginal cost.

${ }^{10}$ There is an upper-bound for $b$. This is to ensure that a firm producing in the foreign country faces positive variable production costs; and the higher cost firm produces a positive output. Thus, the upper-bound is at the minimum of 1 and $(c-t) / \beta$.

${ }^{11}$ This measure depends upon the discount factor, $\delta$. This is because the importance that a firm attaches to a currently incurred fixed cost will be dependent on the way in which it discounts the future. If, for example, a firm values the future equally with the present (this is $\delta=1$ ), the fixed cost will be infinitesimally small in the mind of the firm, compared to the profits accrued in the future.
} 


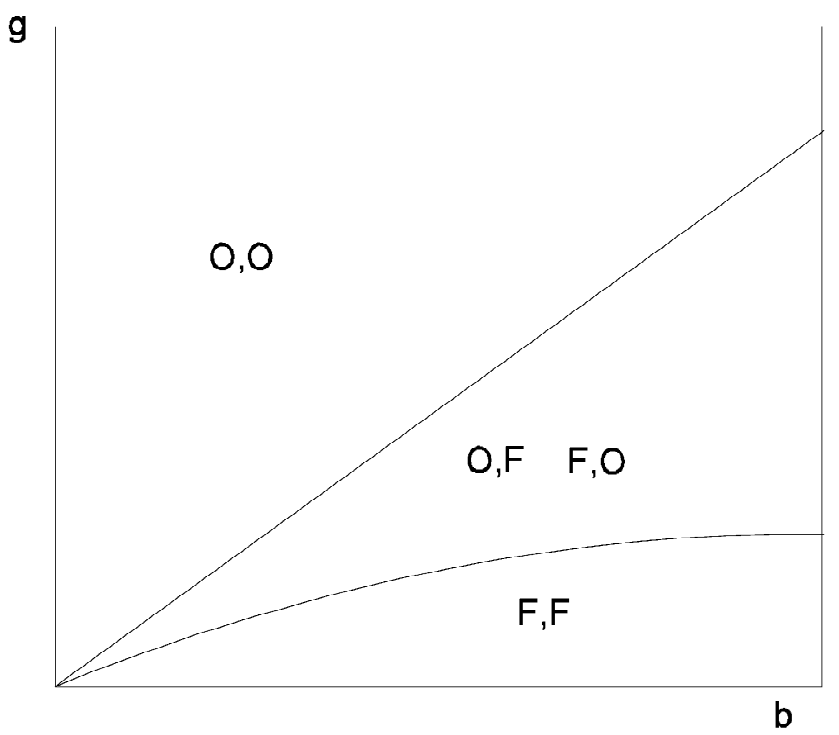

Fig. 1. Collusion excluded.

case, there is no simple prediction about the interdependence between the firms' FDI: it may be positive or negative.

\subsection{Tacit collusion}

\subsubsection{The model of collusion}

Now we permit firms to choose between competitive and collusive behaviour. The latter involves a lowering of industry output below the Cournot level. This raises two issues that are not easily resolved: the way in which industry output will be set; and the way in which industry output will be shared out between firms. If the firms serve the market at the same cost, it is straightforward: industry output is set at the monopoly level given marginal cost; and each firm produces half the total. However, if there is cost asymmetry, it is not so clear. It would be optimal for the low cost firm to produce all of the industry output, and for the other firm to produce nothing. This would maximise industry profits, which could then be shared out in a mutually acceptable way via side-payments from the low to the high cost firm. However, we rule this out on the grounds that side-payments are unrealistic means for informal, tacit collusion to be carried out. Instead, we insist upon each firm's profits being derived only from the margin earned on their output. Thus, both firms must produce positive output for collusive outcomes to be sustained.

First we will resolve the setting of industry output: it will maximise industry 
profits given the share-out rule adopted. Thus, industry output will be the monopoly level given marginal cost at a weighted average of the firms' marginal costs of serving the market (weighted, that is, by market shares).

Now to choose from the wide range of possible share-outs. We want to focus on a set of share-outs that we feel are intuitively appealing. At one extreme there is an equal share-out, i.e. each firm produces half of the total. This is appealing because it is: the Cournot share-out before firms face the FDI decision; in some sense equitable for ex ante symmetric firms; and simply a focal point. At the other extreme is the share-out according to post-FDI Cournot proportions. This is that each colluding firm's output is the same percentage of the industry total as if they were both instead acting competitively. Thus, the low cost firm enjoys a larger market share than the high cost firm. While this set is clearly not exhaustive, we propose that it is nevertheless worthy of special attention. So, we will present results given an equal share-out, and then describe their generality across the rest of our set. Specifically, we will focus on the potential for positive interdependence between the firms' FDI.

Before we present the formal analysis we can perhaps draw a tentative conclusion: collusion is more easily sustained when firms undertake symmetric, rather than asymmetric, FDI. The discussion just presented illustrates that when firms differ in costs, there is much greater potential for confusion (and so disagreement) about the correct manner of collusion. The absence of simple, focal and equitable rules for collusion makes it more difficult for a firm to identify collusive behaviour in a rival ${ }^{12}$. Similarly, it is also unclear if a rival is cheating. On an intuitive level then, one can argue that collusion is less easily sustained when firms differ in costs. In fact, the point that cost asymmetry has such an effect is an old one in the Industrial Organisation literature (see for instance Scherer, 1980), and such a mechanism will be the focus of the formal analysis of the sustainability of collusion presented next.

\subsubsection{Collusion with equal market shares}

If in every period the firms collude, each firm producing half of the total output, the present value of profits for each firm, for each combination of FDI strategies, is as follows:

Firm $i-$ no FDI, $\quad$ Firm $j-$ no FDI: $\quad \pi_{i}=\pi_{j}=\frac{1}{1-\delta} \frac{\beta}{8}$

Firm $i-$ FDI, $\quad$ Firm $j-$ FDI: $\quad \pi_{i}=\pi_{j}=\frac{1}{1-\delta} \frac{\beta(1+b)^{2}}{8}-G$

\footnotetext{
${ }^{12}$ Remember, this is tacit collusion. There is no formal, written agreement between the firms.
} 
Firm $i-\mathrm{FDI}, \quad$ Firm $j-\mathrm{no}$ FDI: $\quad \pi_{i}=\frac{1}{1-\delta} \frac{\beta\left(1+2 b+\frac{3}{4} b^{2}\right)}{8}-G ;$
$\pi_{j}=\frac{1}{1-\delta} \frac{\beta\left(1-\frac{1}{4} b^{2}\right)}{8}$

Firms play an infinitely repeated quantity setting game and we model tacit collusion in the simplest possible way by assuming that it is supported by a grim punishment strategy ${ }^{13}$ (see Friedman, 1971). Each firm chooses between (i) setting the collusive output now and maintaining this until the other player chooses not to collude and (ii) selecting the non-collusive output. If a firm ever chooses not to play the collusive output then its rival moves to its Cournot output forever.

First, say the firms invest in the same way, and so face the same costs. If both firms remain domestic and Firm $j$ colludes, Firm $i$ receives the payoff in (7) if it colludes and:

$$
\pi_{i}=\left(\frac{9}{8}+\frac{8}{9} \frac{\delta}{1-\delta}\right) \frac{\beta}{8}
$$

if it cheats on the collusive understanding. It is straightforward to show that collusion yields at least as high a level of discounted profits as cheating for $\delta \geqslant 9 / 17$. If both firms collude having instead carried out FDI, Firm $i$ receives the payoff in (8). If Firm $i$ cheats while its rival does not, it receives:

$$
\pi_{i}=(1+b)^{2}\left(\frac{9}{8}+\frac{8}{9} \frac{\delta}{1-\delta}\right) \frac{\beta}{8}-G
$$

This comparison implies the same critical discount factor as in the no FDI case, i.e. collusion occurs for $\delta \geqslant 9 / 17$.

Suppose Firm $i$ relocates production abroad while Firm $j$ remains domestic. Then Firm $i$ 's discounted profits if it cheats are:

$$
\pi_{i}=\beta\left[\left(\frac{3}{8}+\frac{7}{16} b\right)^{2}+\frac{\delta}{1-\delta} \frac{(1+2 b)^{2}}{9}\right]-G
$$

The payoff to Firm $j$ if it cheats is:

$$
\pi_{j}=\beta\left[\left(\frac{3}{8}-\frac{1}{16} b\right)^{2}+\frac{\delta}{1-\delta} \frac{(1-b)^{2}}{9}\right]
$$

From these profits we again derive the critical value of $\delta$, above which the firms

\footnotetext{
${ }^{13}$ It is well known that more sophisticated punishments can be used to expand the range of discount factors over which collusion can be supported. (See Vives, 1999, chapter 9 for a recent survey of oligopoly supergames.) We aim in this paper to keep the analysis as simple as possible. However, we conjecture that more sophisticated punishment strategies would not affect our qualitative results.
} 
will find it optimal to collude. In this case, the critical value differs between firms. It is the highest of these values that counts as both firms must be willing to collude for collusion to be sustained. Fig. 2 presents these critical values of $\delta$ in $b, \delta$ space, where:

F,O [Firm $j$ (no FDI)]: this downward sloping curve gives the critical $\delta$ above which Firm $j$ will collude.

F,O [Firm $i$ (FDI)]: this upward sloping curve gives the critical $\delta$ above which Firm $i$ will collude.

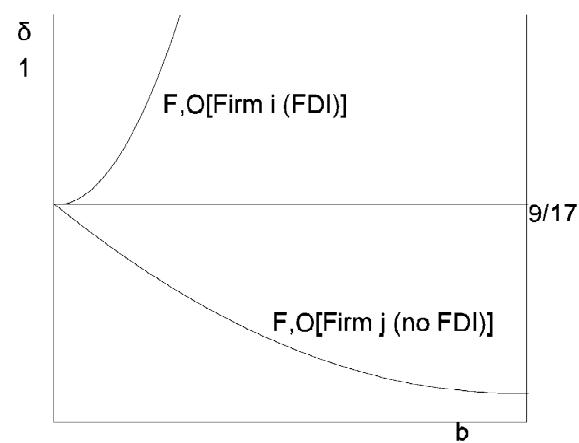

(Fig.2)

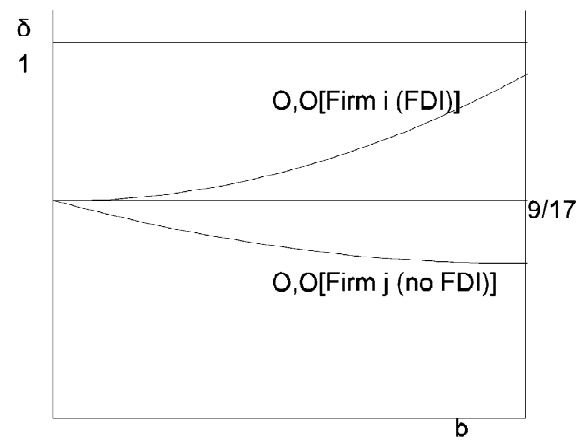

(Fig.4)

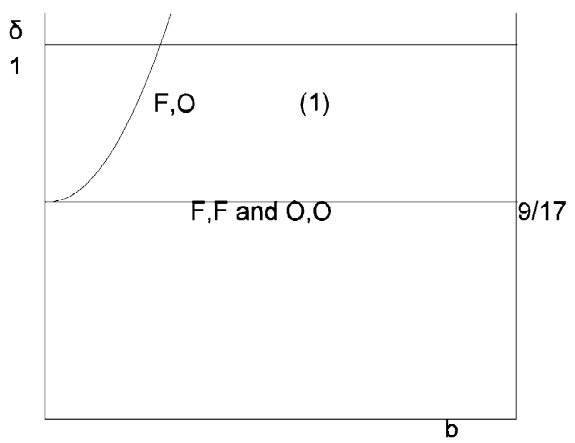

(Fig.3)

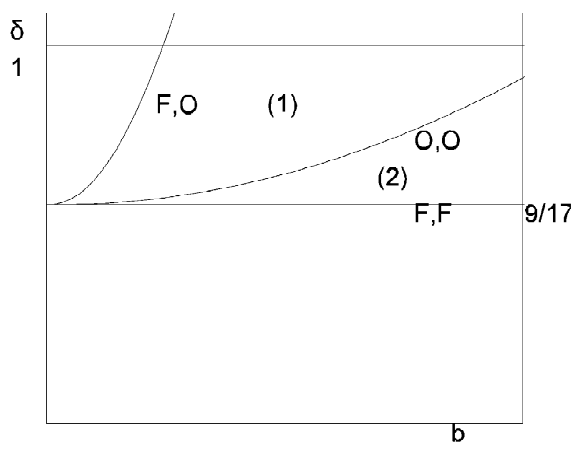

(Fig.5)

Figs. 2, 3, 4 and 5. The sustainability of collusion. Fig. 2 shows the critical values of $\delta$ for collusion to be sustained in F,O. It is the uppermost curve that counts (as both firms must be willing to collude for it to happen). Given this, Fig. 3 summarises the sustainability of collusion for F,O, O,O and F,F (taking the critical values for $\mathrm{O}, \mathrm{O}$ and $\mathrm{F}, \mathrm{F}$ as 9/17). If instead there would be FDI were cheating to occur in a collusive O,O outcome, the critical value for O,O is no longer 9/17; Fig. 4 shows the critical values of $\delta$ for collusion to be sustained in this case; again, it is the uppermost curve that counts. Fig. 5 then summarises the sustainability of collusion for F,O, O,O and F,F in this case. 
For $b>0$, the critical discount factor in order for the firm that invests abroad to collude is above that for the firm that remains domestic. For a given discount factor, the low marginal cost firm, that is the firm that does the FDI when its rival does not, gains relatively least from collusion. Fig. 3 permits one to compare the sustainability of collusion in F,F, O,O and F,O. The configuration of FDI that requires the largest discount factor for collusion is F,O. Thus, according to Fig. 3, symmetric FDI facilitates collusive behaviour.

However, we must also consider the possibility that a firm will wish to change its FDI decision once cheating occurs. The example of this that proves most important is where collusive $\mathrm{O}, \mathrm{O}$ breaks down into competitive $\mathrm{F}, \mathrm{O}^{14}$. Here then, firms act collusively in $\mathrm{O}, \mathrm{O}$, but once cheating has occurred and they are faced with Cournot competition forever more, one of the firms wishes to do FDI. We assume that in this situation, the cheating firm of the previous period (say, Firm $i$ ) will use its earlier knowledge of its plans to cheat to act as a first-mover and undertake FDI before the firms compete next in the marketplace. In this scenario, the sustainability of collusion in $\mathrm{O}, \mathrm{O}$ will be somewhere between that in $\mathrm{F}, \mathrm{O}$ and that in F,F. Thus, collusion is less easily sustained in $\mathrm{O}, \mathrm{O}$ than in F,F. This is because F,F offers a greater commitment by the firms to symmetry in the future. Fig. 4 presents the critical values of $\delta$ in $b, \delta$ space, where:

$\mathrm{O}, \mathrm{O}$ [Firm $j$ (no FDI)]: this downward sloping curve gives the critical $\delta$ above which Firm $j$ will collude.

$\mathrm{O}, \mathrm{O}$ [Firm $i$ (FDI)]: this upward sloping curve gives the critical $\delta$ above which Firm $i$ will collude.

First assume $\delta \geqslant 9 / 17$, but that $b$ is sufficiently large to cause a breakdown of collusion when only one firm engages in FDI ${ }^{15}$. This leaves two possibilities: (1) collusion is sustained only in $\mathrm{O}, \mathrm{O}$ and F,F (associated with region (1) in Figs. 3 and $\left.5^{16}\right)$; (2) collusion is sustained in F,F, but is sustained in $\mathrm{O}, \mathrm{O}$ only so long as

\footnotetext{
${ }^{14}$ The firms will, given other parameter values, switch from O,O to F,F. We do not discuss such a switch in the text in order to make the point (that collusion may not be as stable in $\mathrm{O}, \mathrm{O}$ as it is in $\mathrm{F}, \mathrm{F}$ ) as simply as possible. However, it is possible that collusion is not sustainable in $\mathrm{O}, \mathrm{O}$ given a switch to F,O, but is sustainable given a switch upon cheating to F,F. If so, some part of the region in Fig. 7 devoted to F,F, will also support $\mathrm{O}, \mathrm{O}$ as an equilibrium outcome. This part will be the intersection of the region in Fig. 1 devoted to F,F, and the region in Fig. 6 devoted to F,F; O,O. Thus, the case discussed here gives results that lie somewhere between those of Figs. 6 and 7.

${ }^{15}$ In Fig. 2, this is the region bounded from below by $9 / 17$, from the right by the upper-bound on $b$, from the left by Firm $i$ 's loci of critical values, and from above by one (if one is taken to be the largest reasonable discount factor in such a model).

${ }^{16}$ This is true in the region marked with a (1) in both Fig. 3 and Fig. 5. It requires that the discount factor is such that it is large enough for collusion to be sustained in $\mathrm{O}, \mathrm{O}$ and $\mathrm{F}, \mathrm{F}$, but too small for collusion to be sustained in F,O.
} 
there is no switch to F,O were cheating to occur (associated with region (2) in Fig. $\left.5^{17}\right)$.

(1) In this case we get collusion if there is symmetric investment but not if it is asymmetric. The gains from softening competition act to promote FDI clustering, i.e. when both firms invest or neither does. Fig. 6 presents the equilibrium outcomes in $b, g$ space.

When the fixed cost of setting up a new plant $(g)$ is high, both firms remain domestic. If $g$ is low, but the marginal cost reduction $(b)$ is high, both firms engage in FDI. At high levels of $b$ there is an intermediate range of $g$ that exhibits the same negative interdependence in FDI shown in the competitive case (Section 2.1) - labelled F,O; O,F in Fig. 6. Here, collusion is not sustainable. However, for lower $b$, equilibria in the intermediate range will be such that if one firm does FDI, the other follows as it knows this is the only way to avoid a breakdown in collusion. Indeed given such a breakdown, it will face a relatively low cost competitor.

The key feature of these results is the potential for positive interdependence between the firms' FDI decisions ${ }^{18}$. FDI clustering occurs due to the follow-my-

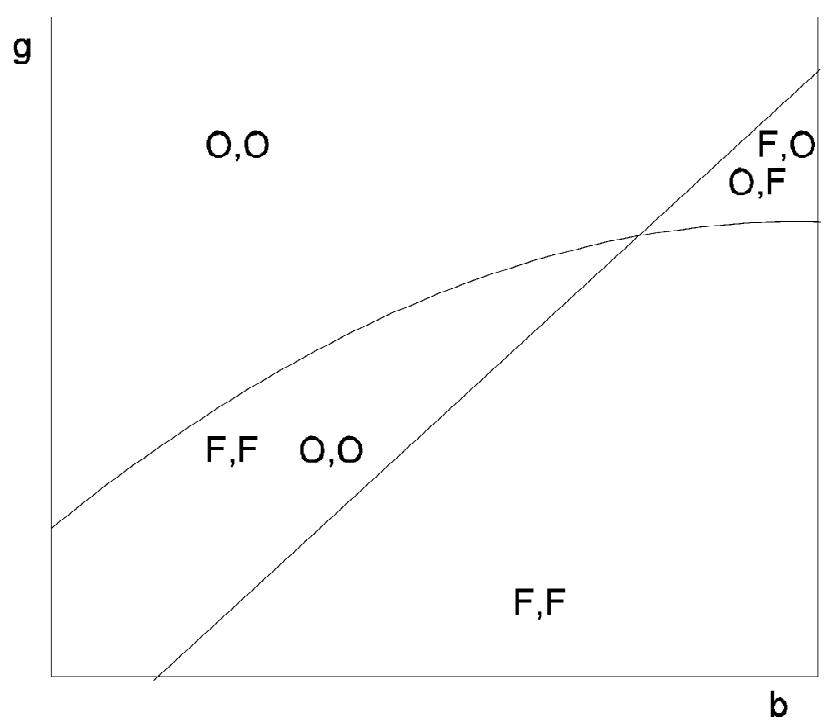

Fig. 6. Collusion sustained only in O,O and F,F: (1).

\footnotetext{
${ }^{17}$ This is true in the region marked with a (2) in Fig. 5. It requires that the discount factor is such that it is large enough for collusion to be sustained in F,F, but too small for collusion to be sustained in $\mathrm{O}, \mathrm{O}$ or $\mathrm{F}, \mathrm{O}$.

${ }^{18}$ It is worth noting that the negative and positive interdependence discussed here are analogous to strategic substitutability and complementarity, respectively. The latter concepts were, however, originally defined for continuous choice variables (see Bulow et al., 1985).
} 
leader behaviour of investors. By comparing Fig. 1 (the competitive case) with Fig. 6, one can see the latter results show a greater prevalence of symmetric FDI (i.e. F,F and $\mathrm{O}, \mathrm{O}$ replace $\mathrm{F}, \mathrm{O}$ and $\mathrm{O}, \mathrm{F}$ ).

(2) In this case, collusion accompanies symmetric FDI ( $\mathrm{O}, \mathrm{O}$ or F,F) so long as that symmetry is not threatened by a breakdown of collusive behaviour. Therefore, owing to the irreversibility of investment, the gains from softening competition act to promote follow-my-leader behaviour where both firms invest (F,F). Fig. 7 presents the equilibrium outcomes in b, g space.

Many features of the results presented in Fig. 6 remain here. Most notably, there is potential for positive interdependence between the firms' FDI decisions. Also, there is again a shift towards symmetric FDI as compared to the competitive case (see Fig. 1). Here though, the shift is more markedly towards F,F than is the case in Fig. 6. Indeed, when comparing Figs. 7 and 1, we have no increased prevalence of O,O. So, the shift towards symmetric FDI is due solely to an increased prevalence of F,F.

So, we have shown that there are gains from collusion; symmetry facilitates collusion; if both firms invest they thereby commit to cost symmetry forever; if neither firm invests, there is symmetry, but it can be broken by FDI were cheating to occur; this potential asymmetry hampers collusion; if collusion is sustained only if both firms invest, this promotes an FDI cluster (F,F).

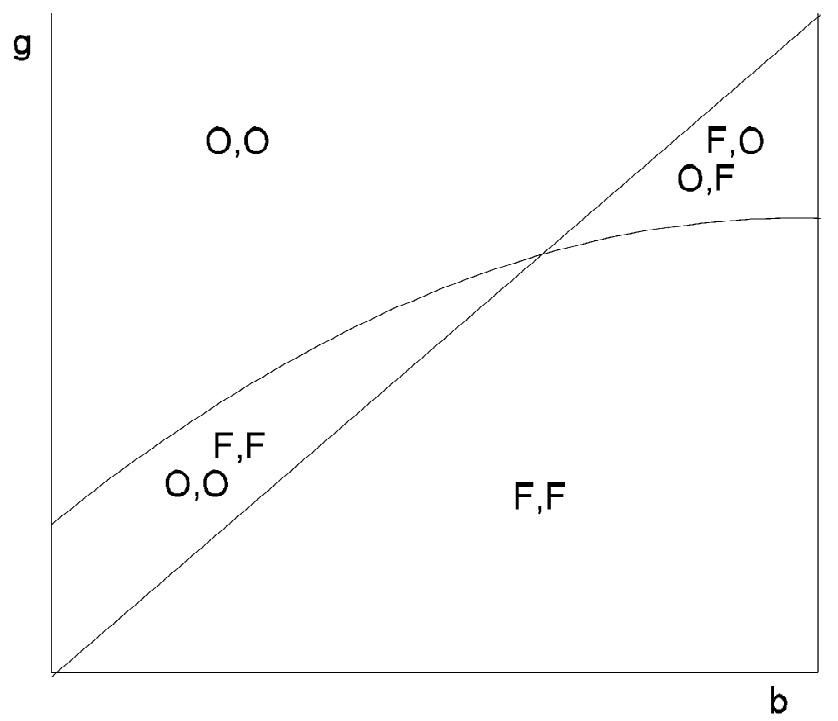

Fig. 7. Collusion sustained in O,O (if there is no FDI given competition) and F,F: (2). 


\subsubsection{Collusion with unequal market shares}

Now let us consider unequal collusive output share-outs when there is asymmetric FDI. Across the set of share-outs described previously (from equal shares to Cournot shares), two features of the results just presented hold true: collusion is more easily sustained when the firms have symmetric FDI strategies; and there exists some range of parameter values for which there is a positive interdependence between the firms' FDI. Thus, the potential for a positive interdependence, and the resulting clustering of FDI, exists across the entire set of share-outs. Clearly, for this potential follow-my-leader behaviour to occur, there must be a suitable configuration of costs, demand conditions and discount factors. Outside the set of intuitively appealing share-outs that we have focussed upon, the two main features of the results do not necessarily hold true. Where they do not ${ }^{19}$, there exists only the negative interdependence in FDI akin to that illustrated in the competitive case (Section 2.1).

\section{Conclusion}

We have presented a simple, rather stylised model of firms' decisions to serve their domestic market using foreign production. When the two firms are restricted to competitive behaviour, there is a negative interdependence between their FDI, i.e. one firm undertaking FDI reduces the incentive for its rival to follow suit. If the firms are instead permitted to tacitly collude, and find it possible to do so only if they execute symmetric FDI strategies, there is potential for positive interdependence in FDI. This results in follow-my-leader behaviour and FDI clusters. It is also possible that the firms will only collude if they both undertake FDI. This further promotes symmetric outcomes where both firms invest abroad. The presence of such behaviour depends on both the way in which industry output is shared out in collusive outcomes, and the values taken by cost, demand, and discounting parameters.

The point made here is not that symmetric FDI necessarily yields collusion (it does not), or that colluding firms will undertake follow-my-leader FDI (that depends upon the output share-out; see Section 2.2.3). It is simply that, in a tacit collusion equilibrium, there are incentives for follow-my-leader FDI that are absent when firms follow one-shot non-cooperative Cournot strategies. Further-

\footnotetext{
${ }^{19}$ Simulations show that there do exist market share combinations that actually increase the stability of collusion above the level in the symmetric investment cases. These involve the low cost firm getting an even higher market share under collusion than under competition. If firms were indeed to agree to such a split it would further strengthen the negative interdependence among firms' FDI illustrated in the competitive case (Section 2.1).
} 
more, we have shown that in our simple model, this potential exists given intuitively appealing collusive conduct.

Follow-my-leader FDI can lead to firms clustering in one or other location. At first glance, this may suggest that FDI flurries and FDI clusters provide empirical support for positive interdependence in FDI decisions. However, there is a need to be very cautious about this. These flows may also be motivated by low cost foreign production and one must also distinguish between clustering due to follow-my-leader behaviour and other economic geography motivations. In addition, apart from sustaining collusion, there are other possible reasons for follow-my-leader FDI. We saw that Knickerbocker (1973) identified uncertainty and risk aversion as another reason for positive interdependence in FDI and this is formalised by Head et al. (forthcoming). We regard these two explanations as complementary.

Finally, as stated briefly in the introduction, one can readily extend the model beyond FDI. Application to any investment decision that can be characterised as a fixed outlay in exchange for a per-unit saving is straightforward. For example, cost-reducing research and development, and setting up a distribution network spring to mind. So, there may be an illustration here of a potential for follow-myleader behaviour in more than one of the ways firms interact.

\section{Acknowledgements}

This paper was written while Stephen Pavelin was a post-doctoral research fellow at UCD. The post is part of a CEPR research network: FDI and the Multinational Corporation (contract no.: ERBFMRXCT-97-0585), funded by the TMR programme of the European Commission. The authors would like to thank Frank Barry, Kristof Dascher, Tom Giblin, Peter Neary and three anonymous referees for helpful comments - the usual disclaimer does, of course, apply.

\section{References}

Bernheim, B.D., Whinston, M.D., 1990. Multimarket contact and collusive behaviour. RAND Journal of Economics 21, 1-26.

Buckley, P.J., Casson, M., 1981. The optimal timing of foreign direct investment. Economic Journal 91, 75-87.

Bulow, J., Geanakoplos, J., Klemperer, P.D., 1985. Multimarket oligopoly: strategic substitutes and complements. Journal of Political Economy 93, 488-511.

Caves, R.E., 1996. Multinational Enterprise and Economic Analysis, 2nd Edition. Cambridge, Cambridge University Press.

Caves, R.E., Pugel, T.E., 1980. Intra-industry differences in conduct and performance: viable strategies in US manufacturing industries. Salomon Brothers Center Monograph Series in Finance and Economics. New York University Graduate School of Business Administration. 
Friedman, J., 1971. A noncooperative equilibrium for supergames. Review of Economic Studies 38, $1-12$.

Head, K., Mayer, T., Ries, J., forthcoming. Revisiting oligopolistic reaction: are FDI decisions strategic complements? Journal of Economics \& Management Strategy.

Hennart, J.-F., Park, Y.-R., 1994. Location, governance, and strategic determinants of Japanese manufacturing investments in the United States. Strategic Management Journal 15, 419-436.

Horstmann, I.J., Markusen, J.R., 1987. Strategic investments and the development of multinationals. International Economic Review 28, 109-121.

Horstmann, I.J., Markusen, J.R., 1992. Endogenous market structures in international trade (natura facit saltum). Journal of International Economics 32, 109-129.

Ito, K., Rose, E.L., 1998. Industry Competition and Global Consolidation: Multiple Market Competition in the Tire Industry. Australian Centre for International Business DP.

Knickerbocker, F.T., 1973. Oligopolistic Reaction and Multinational Enterprise. Harvard University, Boston.

Motta, M., 1992. Multinational firms and the tariff jumping argument: a game theoretical analysis with some unconventional conclusions. European Economic Review 36, 1557-1571.

Scherer, F.M., 1980. Industrial Market Structure and Economic Performance. Rand-McNally, Chicago.

Scott, J.T., 1993. Purposive Diversification and Economic Performance. Cambridge University Press, Cambridge.

Smith, A., 1987. Strategic investment, multinational corporations and trade policy. European Economic Review 31, 89-96.

Vives, X., 1999. Oligopoly Pricing: Old Ideas and New Tools. MIT Press, Cambridge.

$\mathrm{Yu}$, C.-M., Ito, K., 1988. Oligopolistic reaction and foreign direct investment: the case of the US tire and textiles industries. Journal of International Business Studies 19, 449-460. 